\title{
QX-OH/Levobupivacaine: A Structurally Novel, Potent Local Anesthetic Produces Fast-Onset and Long-Lasting Regional Anesthesia in Rats
}

\author{
Yang Yang ${ }^{1,2}$, Chiyi Wang ${ }^{1,2}$, Jin Liu ${ }^{1,2}$, Daqing Liao ${ }^{2}$, Wensheng Zhang $\mathbb{D}^{1,2}$, Cheng Zhou ${ }^{2}$ \\ 'Department of Anesthesiology, West China Hospital, Sichuan University, Chengdu, 61004I, People's Republic of China; ${ }^{2}$ Laboratory of Anesthesia \\ and Critical Care Medicine, National-Local Joint Engineering Research Centre of Translational Medicine of Anesthesiology, West China Hospital, \\ Sichuan University, Chengdu, 61004I, Sichuan, People's Republic of China \\ Correspondence: Cheng Zhou, Laboratory of Anaesthesia \& Critical Care Medicine, Translational Neuroscience Center, The Research Units of West \\ China (2018RU012), Chinese Academy of Medical Sciences, West China Hospital of Sichuan University, Chengdu, 6I004I, People's Republic of China, \\ Tel +8I-28-85I64I45, Fax +8I-28-85I64039, Email zhouc@I63.com; Wensheng Zhang, Department of Anaesthesiology and Laboratory of \\ Anaesthesia \& Critical Care Medicine, Translational Neuroscience Center, West China Hospital of Sichuan University, Chengdu, 6I004I, Sichuan, \\ People's Republic of China, Tel/Fax +8I-28-85I64I44, Email zhang_ws@scu.edu.cn
}

Purpose: Local anesthetics (LAs) are an important alternative for postoperative analgesia; however, the short duration of LAs limits their use. Thus, we previously developed LL-1, a mixture of QX-OH and levobupivacaine (LB) that produces regional anesthesia for more than $10 \mathrm{~h}$ in rats. The aim of this study is to investigate the long-acting mechanism of LL-1 in vivo and in vitro.

Methods: Regional anesthetic effects and local toxicity of the LL-1, QX-OH and LB treatment groups were investigated in a sciatic nerve block rat model. Whole-cell patch-clamping recordings were used to measure the inhibition $\mathrm{Na}_{\mathrm{v}}$ currents $\left(I_{N a}\right)$ in ND7/23 cells. Results: The onset of LL-1 (35mM QX-OH+10mM LB) and $10 \mathrm{mM} \mathrm{LB}$ was $10 \mathrm{~min}$, which was much faster than $35 \mathrm{mM}$ QX-OH (27 $[18,60] \mathrm{min}, \mathrm{t}[12]=-4.535, \mathrm{p}=0.001)$. The duration of LL-1 (35mM QX-OH+10 mM LB) was significantly longer than $35 \mathrm{mM}$ QX$\mathrm{OH}$ or $10 \mathrm{mM}$ LB alone $(\mathrm{F}[3,35]=191.336, \mathrm{p}<0.0001)$. No differences in local tissue toxicity were found between LL-1 and LB. In patch-clamping recordings, $5 \mathrm{mM}$ QX-OH produced $\sim 20 \%$ inhibition of $I_{\mathrm{Na}}$ currents. LB at $40 \mu \mathrm{M}$ inhibited $I_{\mathrm{Na}}$ by $65.51 \% \pm 3.63 \%$, while QX-OH $2 \mathrm{mM}+\mathrm{LB} 40 \mu \mathrm{M}$ inhibited $I_{\mathrm{Na}}$ by $77.37 \% \pm 3.36 \%(\mathrm{t}[14]=2.358, \mathrm{p}=0.025)$, and QX-OH $5 \mathrm{mM}+\mathrm{LB} 40 \mu \mathrm{M}$ inhibited $I_{\mathrm{Na}}$ by $83.88 \% \pm 1.57 \%(\mathrm{t}[13]=4.191, \mathrm{p}=0.0003)$. Furthermore, $I_{\mathrm{Na}}$ inhibition by QX-OH+LB was more persistent than that of LB alone during washout.

Conclusion: LL-1 can produce an additive and stable inhibition of $\mathrm{Nag}_{\mathrm{v}}$ currents, which can contribute to the long-lasting regional anesthetic action.

Keywords: long-lasting local anesthetics, QX-OH, levobupivacaine, voltage-gated sodium channel, $\mathrm{Na}_{\mathrm{v}}$

\section{Introduction}

Local anesthetics (LAs) are an important alternative for postoperative analgesia, due to the limitations due to adverse effects associated with opioid use such as respiratory depression, nausea, vomiting, and constipation that can reduce patient satisfaction and safety. ${ }^{1}$ However, the duration of currently used LAs is insufficient to meet the demand for postoperative pain management. ${ }^{2-4}$ As a result, it is necessary to develop novel LAs with long-acting properties and tolerable toxicity.

To improve the postoperative analgesia, we developed QX-OH, a hydroxyethyl derivative of QX-314, by substituting a hydroxyl group (-OH) for one of the hydrogen groups (-H) in QX-314. ${ }^{5,6}$ In rats, it has previously been reported that QX-OH produces longer-lasting analgesia with less local tissue damage than QX-314 in the sciatic nerve block model. ${ }^{7}$ QX-OH, conversely, has a half-hour onset period, which limits its clinical use. ${ }^{7}$ In the rat sciatic nerve block model, combining QX-OH with levobupivacaine (LB) (named LL-1) may elicit sensory block lasting 9 hours after knee surgery and with regional anesthesia lasting 17 hours, with an onset of less than 10 minutes. ${ }^{8-10}$ The mechanism by which LL-1 
provides a long-lasting localized anesthetic effect, as well as the pharmacological interaction between QX-OH and LB, remains unexplained.

The voltage-gated sodium channel $\left(\mathrm{Na}_{\mathrm{v}}\right)$ is a critical ion channel required for initiation and propagation of the action potential. ${ }^{11}$ Almost all of the local anesthetics used in clinical practice are $\mathrm{Na}_{\mathrm{v}}$ channel blockers. ${ }^{12-16}$ However, it is unknown whether QX-OH can inhibit $\mathrm{Na}_{\mathrm{v}}$ channels alone or in combination with LB.

The purpose of this study was to examine the interaction of QX-OH and LB on $\mathrm{I}_{\mathrm{Na}}$ inhibition and to compare the regional anesthetic effects and local toxicity of LL-1 with QX-OH and LB at relative concentrations in a standard sciatic nerve block model in rats.

\section{Materials and Methods}

\section{Animals}

Adult male and female Sprague-Dawley rats weighing between 250 and $300 \mathrm{~g}$, aged between 2 and 3 months, were purchased from Chengdu Dossy Biological Technology Co., Ltd. (Chengdu, China). The animals were housed in a standard laboratory animal husbandry with a 12-hour light/dark cycle and free access to food and water. All experimental procedures in this study meet the guidelines of the Care and Use of Laboratory Animals by the US National Institutes of Health (NIH Publications No. 80-23, revised 1996). The Committee of Animal Care of the West China Hospital (Sichuan University, Chengdu, China) (Ethical Approval Number, 2015014A) approved all experimental protocols.

\section{ND7/23 Cells Expressing Rat Sodium Channels}

ND7/23 is a hybrid cell line of rat DRG and mouse N18Tg2 neuroblastoma, which is widely used for pharmacological measurement of the $\mathrm{I}_{\mathrm{Na}} \cdot{ }^{17}$ ND7/23 cells (Binhui Biology Co., Shanghai, China) were cultured in DMEM (GIBCOInvitrogen, Karlsruhe, Germany) containing $10 \% \mathrm{FBS}$ and $1 \%$ penicillin/streptomycin (GIBCO-Invitrogen) in an $37^{\circ} \mathrm{C}$ and 5\% carbon dioxide environment. ${ }^{18}$ Electrophysiological recordings were performed 48 hours post-plating.

\section{Electrophysiological Recordings}

Whole-cell patch-clamp recordings were performed at room temperature $\left(\sim 24-25^{\circ} \mathrm{C}\right)$ using an Axopatch $200 \mathrm{~B}$ amplifier (Axon Instruments Inc, Foster City, CA, USA). Recording glass electrodes (B150-86-7.5, Sutter Instrument, Novato, CA, USA) were pulled to a resistance of 4-5 M $\Omega$ by a Micropipette Puller (P-97, Sutter Instrument). The internal solution contained (mM): CsF 120, NaCl 10, HEPES 10, EGTA 10, TEA-Cl 10, $\mathrm{CaCl}_{2} 1, \mathrm{MgCl}_{2}$ 1, Mg-ATP 3, and GTP 0.3, at $\mathrm{pH} 7.3$ adjusted with $\mathrm{CsOH}$, and was filtered using a $0.2-\mu \mathrm{m}$ pore membrane filter before pouring into the glass electrodes. The external solution contained (mM): $\mathrm{NaCl}$ 140, HEPES 10, $\mathrm{KCl} 3, \mathrm{MgCl}_{2} 1, \mathrm{CaCl}_{2}$ 2, TEA-Cl 20, D-glucose 5, at pH 7.38 adjusted with $\mathrm{NaOH}$. The study solutions were applied using an in-house constructed gravitydriven application system. The tip of the perfusion cannula was placed near the target cell within $200 \mu \mathrm{m}$. Membrane current signals were filtered at $10 \mathrm{~Hz}$ and sampled at $20 \mathrm{kHz}$. $I_{\mathrm{Na}}$ was recorded by depolarization to $-10 \mathrm{mV}$ from holding potential of $-70 \mathrm{mV}$ in voltage-clamp mode.

\section{Chemicals}

QX-OH was synthesized in our laboratory based on the protocols of a registered patent (Invention Patent, China, ZL201410688865.1) ${ }^{8}$ (Figure 1). QX-314, levobupivacaine (LB), and lidocaine were purchased from Sigma-Aldrich Canada Ltd (Oakville, ON, Canada). QX-OH was diluted to working concentrations by ultrapure water (Milli-Q ${ }^{\circledR}$ integral water purification system, Merck Millipore, Germany) in animal experiments and by the external solution in patch-clamping recordings immediately before experiments.

\section{Sciatic Nerve Block Model}

Rats were randomly assigned to four groups ( $\mathrm{n}=8$ /each group) and received LL-1 (a combination of $35 \mathrm{mM} \mathrm{QX-OH}$ and $10 \mathrm{mM}$ levobupivacaine), $35 \mathrm{mM}$ QX-OH, and $10 \mathrm{mM}$ levobupivacaine (equivalent to $\sim 0.3 \%$ ) at a volume of $200 \mu \mathrm{L}$, respectively. Under $2 \%$ isoflurane general anesthesia, rats were shaved, disinfected, and injected with study solutions 


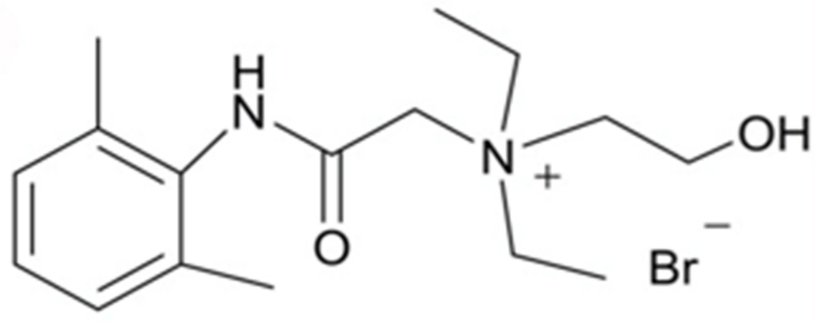

Figure I Chemical structure of QX-OH. This figure illustrated the chemical structure of QX-OH.

vertically into the bone layer below the midpoint between the largest trochanter and the ischial tuberosity of the left leg. ${ }^{19}$ Neurobehavioral evaluation was performed 10, 18, 24, and $30 \mathrm{~min}$, and 1, 2, 4, 6, 8, 10, 12, 18, and 24 hours after injection.

The sensory block was assessed using a hotplate (Model RB-200 Hotplate Analgesia Meter; Chengdu Technology \& Market Co., Ltd., China). Setting the temperature at $\sim 55^{\circ} \mathrm{C}$, the hotplate was used to inflict thermal noxious stimulation on rats and the cut-off time of thermal stimulation was set at $12 \mathrm{~s}$ to avoid burns. ${ }^{20}$ The time from the onset of thermal stimulation to the withdrawal response of the rat was defined as the paw withdrawal latency (PWL). The baseline PWL of rats was measured on 3 consecutive days before the experiments and calculated as the mean value of the 3 days. Then, PWL was calculated as the percentage maximal possible effect $(\% \mathrm{MPE})$ according to the following equation: $(\% \mathrm{MPE})=($ test PWL - baseline)/(cutoff time - baseline) $* 100 \%{ }^{21}$ The $\%$ MPE of above $50 \%$ was defined as an effective sensory block, and the complete sensory block was defined as \%MPE reaching 100\%. The onset time of the sensory block was defined as the time from injection to the first time when \%MPE was more than 50\% (10 min was the minimal time required for recovery from isoflurane anesthesia). The offset time was defined as the first time when \%MPE again decreased to lower than $50 \%$. The duration from onset to offset of sensory block was defined as the duration of sensory block.

The motor function of the injected leg was assessed by the postural extensor thrust test. ${ }^{7}$ An electronic scale was used to measure the muscle strength of the injected hind limb in an upright posture and the force that the paw generated against the platform of the scale was the strength of the limb. Before the experiments, we measured the muscle strength for 3 consecutive days and calculated the mean value as the baseline. After injection of study solutions, the effective motor block was defined as the strength of the limb decreased by more than $50 \%$ compared to baseline. The onset of motor block was defined as the time from the injection to the time of the first detectable effective block (10 min was the minimal time required for recovery from isoflurane anesthesia). The offset was defined as the time when the strength of the limb again increased to more than $50 \%$. The duration from the onset to offset of motor block was defined as the duration of motor block.

\section{Histological Analysis}

Samples of sciatic nerves and adjacent muscle that were exposed to study solutions were selected on the 7th and 14th days after recovery of the sciatic nerve block. Eight rats in each group were randomly euthanatized on the 7 th or 14 th day, respectively. Pathological section, hematoxylin-and-eosin (HE) staining, and fast blue staining were performed according to standard steps. ${ }^{22}$ Two skilled technicians blinded to the treatment of rats evaluated the degree of the inflammation, fibrosis, degeneration within epineurium, the inflammation, hemorrhage, fibrosis outside epineurium, and the inflammation of muscle using the Light Microscopy Imager A2 (Carl Zeiss, Germany). Stained tissues were scored according to the following scale: 0 , indicated normal; 1 indicated $\sim 0-25 \%$ of the area involved; 2 indicated $\sim 25-50 \%$ of the area involved; 3 indicated $\sim 50-75 \%$ of the area involved; and 4 indicated $\sim 75-100 \%$ of the area involved. ${ }^{7,23}$

\section{Statistical Analysis}

Data were plotted and analyzed using SPSS software version 24.0 (IBM Corp., Armonk, NY, USA), Origin (OriginLab Corporation, MA, USA), and GraphPad Prism (GraphPad Software, San Diego, California, USA). The normal distribution of data was confirmed using the Shapiro-Wilk test. Continuous data were reported as mean \pm SEM or median 
(Interquartile range) as appropriate. Categorical data were analyzed using the Chi-square test or Fisher's exact test. A P-value of $<0.05$ was recognized as statistically significant. Differences were analyzed using the Student's $t$-test and Mann-Whitney $U$-test with post-hoc Bonferroni analysis.

\section{Results}

\section{LL-I Blocked Na+ Currents in ND7/23 Cells QX-OH Alone Produced a Small Inhibition of the $I_{\mathrm{Na}}$}

To evaluate the main components of LL-1, we performed inhibition comparisons between QX-OH and its prototype QX314 on $I_{\mathrm{Na}}$, lidocaine was used as the positive control, and the extracellular solution was set as the blank control (Figure 2A). After an extracellular perfusion for $10 \mathrm{~min}$, lidocaine at a concentration of $5 \mathrm{mM}$ produced a significant inhibition of $I_{\mathrm{Na}}$ by $88.08 \% \pm 3.79 \%$, QX-OH at $5 \mathrm{mM}$ inhibited $I_{\mathrm{Na}}$ by $19.28 \% \pm 3.63 \%, 5 \mathrm{mM}$ QX-314 inhibited $I_{\mathrm{Na}}$ by $9.48 \% \pm 2.05 \%$, and in the control group with an only extracellular solution produced inhibition of $I_{\mathrm{Na}}$ by $7.05 \% \pm$

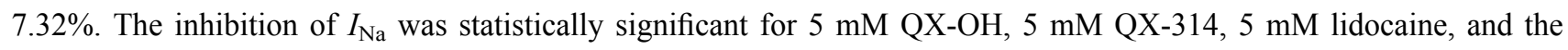
blank control group (F $(3,28)=192.36, \mathrm{p}<0.0001$, one-way ANOVA with Bonferroni post hoc test). The inhibition of $I_{\mathrm{Na}}$ by $5 \mathrm{mM}$ QX-OH was lower than that obtained with lidocaine $5 \mathrm{mM}(\mathrm{t}(10)=17.638, \mathrm{p}<0.001$; two independent sample $t$-test). No significant differences were detected in the inhibition of $I_{\mathrm{Na}}$ at $5 \mathrm{mM}$ QX-OH and $5 \mathrm{mM}$ QX-314 $(\mathrm{t}(10)=$ $-1.962, \mathrm{p}=0.07$; two independent sample $t$-test), or for $5 \mathrm{mM} \mathrm{QX}-314$, or the control group $(\mathrm{t}(11)=0.239, \mathrm{p}=0.814$; two independent sample $t$-test) (Figure 2B). The Figure 2C showed the currents down trend in four groups after perfusion with drugs.

\section{A}

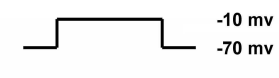

Lidocaine $5 \mathrm{mM}$

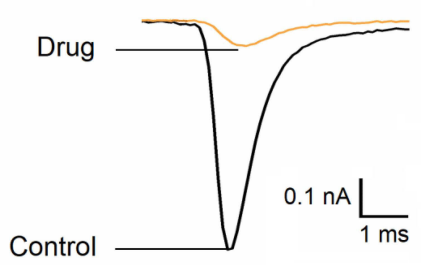

B

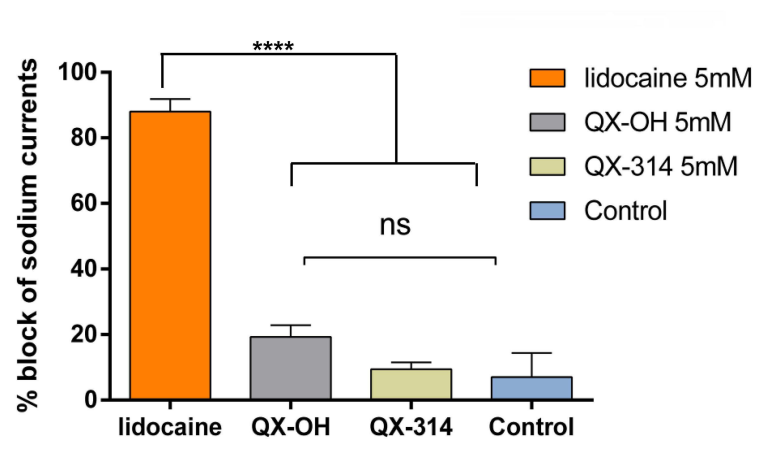

QX-314 $5 \mathrm{mM}$
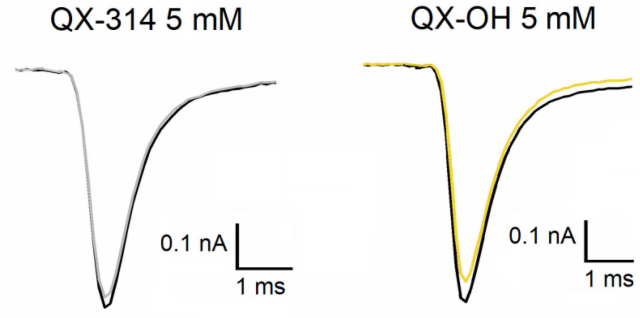

C

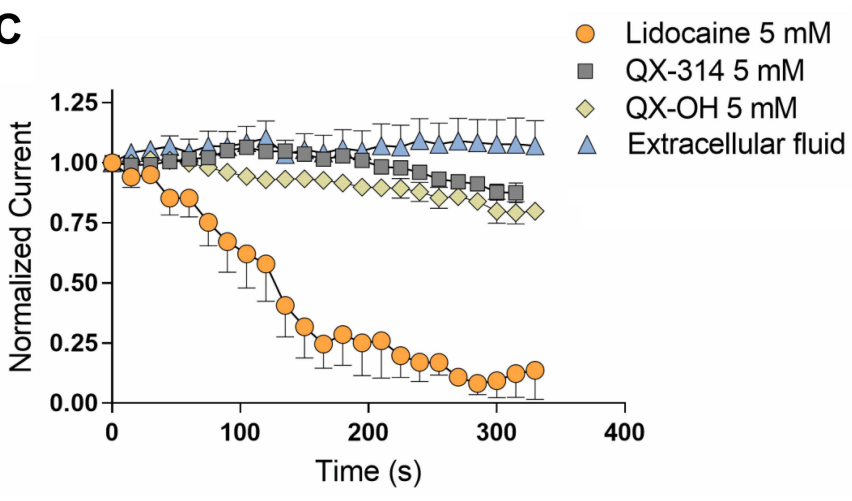

Control

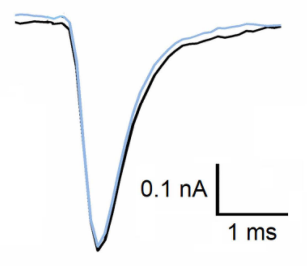

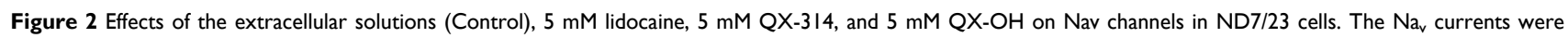
recorded in ND7/23 cells. The $\mathrm{Na}_{\mathrm{v}}$ currents were depolarized from $-90 \mathrm{mV}$ to $-10 \mathrm{mV}$. (A) $\mathrm{Na}_{\mathrm{v}}$ currents traces in the presence of extracellular fluid (Control), $5 \mathrm{mM}$ lidocaine, $5 \mathrm{mM}$ QX-3|4, and $5 \mathrm{mM}$ QX-OH were recorded. (B) Time course plot of the sodium current ratio in the application of extracellular fluid, lidocaine, QX-3/4, and QX-OH under the same repeating protocol $(n=6-1 \mathrm{l} /$ per group). The normalized currents are the ratio of current amplitudes of each pulse observed in each solution as applied to the stable current amplitudes of pre-solution application. (C) Bar diagrams evidencing the inhibition rates of sodium currents induced by the application of

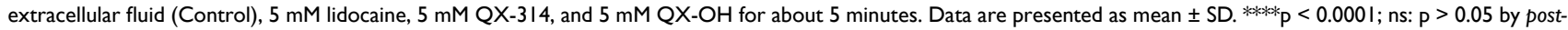
hoc of Least-Significant Difference Test (LSD). 


\section{Combined QX-OH and LB Produced an Additive and Persistent Inhibition of $I_{\mathrm{Na}}$}

To evaluate the interaction of QX-OH and LB on inhibition of the $I_{\mathrm{Na}}$, the $\mathrm{IC}_{50}$ (median inhibitory concentration) of LB was also determined by fitting the averaged dose-response curve with the Hill equation, which yielded an $\mathrm{IC}_{50}$ of $66.85 \pm$ $1.77 \mu \mathrm{M}$ with a Hill coefficient of -1.529 for the $I_{N a}(\mathrm{n}=5-8)$ (Figure 3A and B). However, we determined that QX-OH could only provide a small inhibition of the $I_{\mathrm{Na}}$ at $5 \mathrm{mM}$, while at $2 \mathrm{mM}$ the $I_{\mathrm{Na}}$, changed modestly, thus we could not evaluate the $\mathrm{IC}_{50}$ of the QX-OH directly.

Next, we evaluated different combinations of $\mathrm{LB}+\mathrm{QX}-\mathrm{OH}$ to determine any combinatory effects. LB at a concentration of $40 \mu \mathrm{M}$ (slightly lower than $\mathrm{IC}_{50}$ ) was used for combination exposures. The initial concentration of QX-OH used in the combination was set at $140 \mu \mathrm{M}$ based on the ratio of QX-OH and LB in LL-1 (3.5:1) in vivo. In addition, two other higher concentrations of QX-OH ( $2 \mathrm{mM}$ and $5 \mathrm{mM}$ ) were also tested. In total, four groups were evaluated: $40 \mu \mathrm{M} \mathrm{LB}$ alone; $40 \mu \mathrm{M} \mathrm{LB}+140 \mu \mathrm{M}$ QX-OH; $40 \mu \mathrm{M} \mathrm{LB}+2 \mathrm{mM}$ QX-OH; and $40 \mu \mathrm{M} \mathrm{LB}+5 \mathrm{mM}$ QX-OH.

To compare the effects of different mixing ratios of bupivacaine and $\mathrm{QX}-\mathrm{OH}$, we performed inhibition comparisons among LB $40 \mu \mathrm{M}$ alone, LB $40 \mu \mathrm{M}+\mathrm{QX}-\mathrm{OH} 140 \mu \mathrm{M}$, LB $40 \mu \mathrm{M}+\mathrm{QX}-\mathrm{OH} 2 \mathrm{mM}$ and LB $40 \mu \mathrm{M}+\mathrm{QX}-\mathrm{OH} 5 \mathrm{mM}$ (Figure 3D). The inhibition of the $I_{\mathrm{Na}}$ was significantly different among the four groups $(\mathrm{F}(3,52)=8.248, \mathrm{p}=0.0001$, one-way ANOVA with the Bonferroni post hoc test) (Figure 3C). The inhibition of the $I_{\mathrm{Na}}$ by LB $40 \mu \mathrm{M}+\mathrm{QX}-\mathrm{OH} 140$ $\mu \mathrm{M}(64.38 \% \pm 3.50 \%)$ was similar to the effect produced by LB $40 \mu \mathrm{M}$ alone $(65.51 \% \pm 3.63 \%, \mathrm{t}[12]=-0.223, \mathrm{p}=0.825$; two independent sample $t$-test) (Figure 3C). LB $40 \mu \mathrm{M}+\mathrm{QX}-\mathrm{OH} 2 \mathrm{mM}$ produced a larger inhibition of $I_{\mathrm{Na}}(77.37 \%$

A
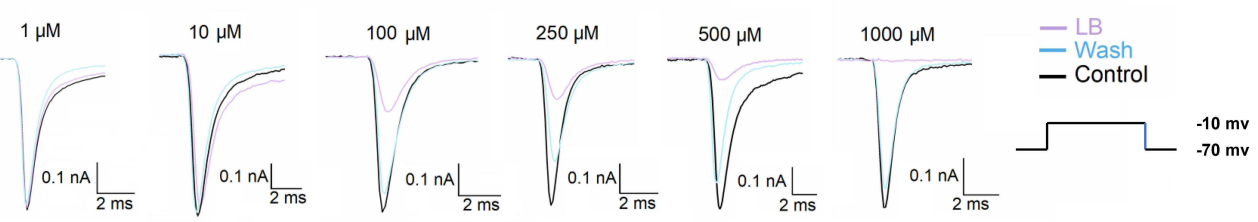

B

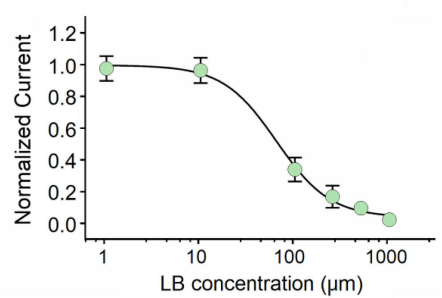

C
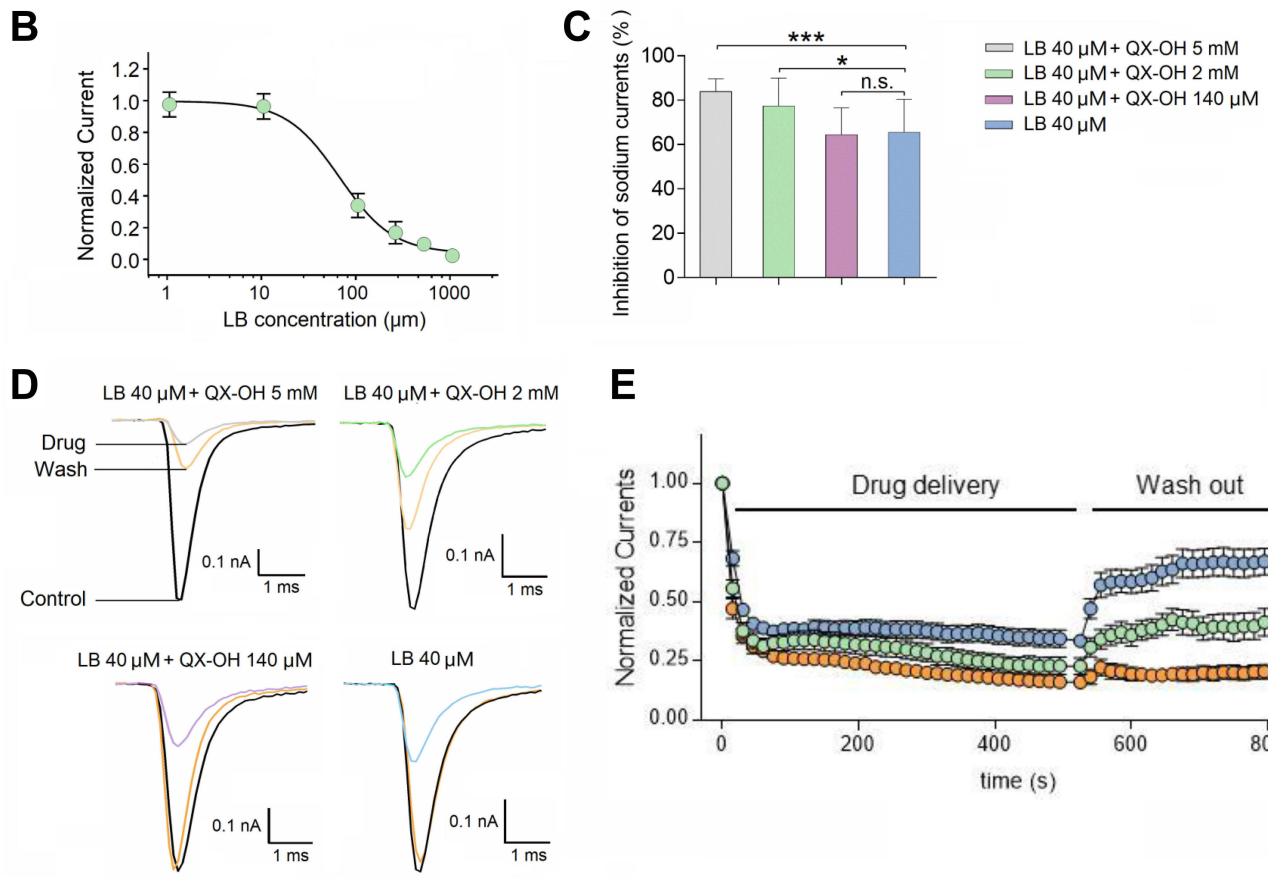

E
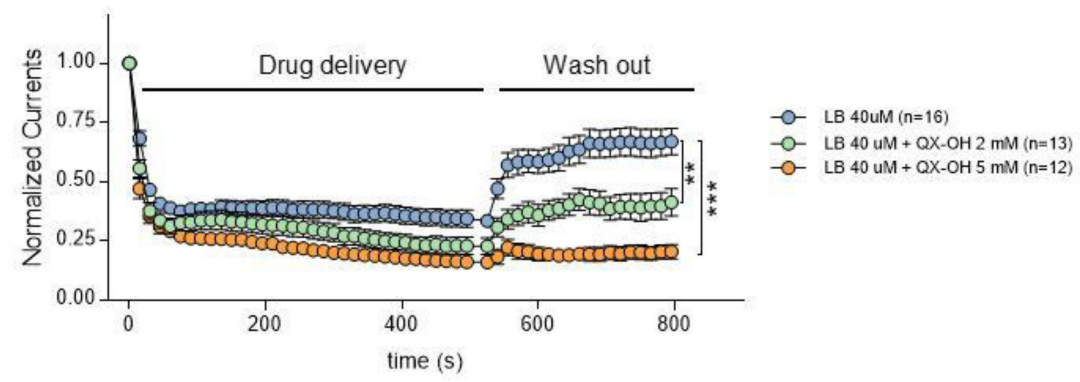

Figure 3 Combination of QX-OH and LB produces additive and constant inhibition of $I_{\mathrm{Na}}$. Representative current traces of a series of LB-induced block of sodium currents. (A) The dose-response curve of LB-induced block of sodium currents. The black curve represents the Hill fit. (B) Bar diagrams showing the inhibition of sodium currents induced by the application of $40 \mu \mathrm{M} \mathrm{LB}$ combinedly with $5 \mathrm{mM}$ QX-OH, $40 \mu \mathrm{M} \mathrm{LB}$ combinedly with $2 \mathrm{mM}$ QX-OH, $40 \mu \mathrm{M}$ LB combinedly with I40 $\mu \mathrm{M}$ QX-OH, and $40 \mu \mathrm{M}$ LB alone for $\sim 5$ minutes (C). (D) Representative sodium current traces. The sodium currents in the presence of $40 \mu M$ LB combined with 5 mM QX-OH, $40 \mu M$ LB combined with $2 \mathrm{mM}$ QX-OH, $40 \mu \mathrm{M}$ LB combined with $140 \mu \mathrm{M} \mathrm{QX}-\mathrm{OH}$, and $40 \mu \mathrm{M}$ LB alone are recorded. (E) The time course plot of sodium current ratio changes induced by $40 \mu \mathrm{M}$ LB combined with $5 \mathrm{mM}$ QX-OH (Orange), $40 \mu \mathrm{M}$ LB combined with $2 \mathrm{mM} \mathrm{QX}-\mathrm{OH}$ (green), and $40 \mu \mathrm{M}$ LB alone (blue) during drug delivery and washout. The normalized currents are the ratio of current amplitudes of each pulse in during drug delivery and washout compared to the stable current amplitudes of presolution application. Data are presented as mean \pm SD. $*^{* *} p<0.001$; **p $<0.0$ I; ${ }^{*} p<0.05$; ns: $p>0.05$ by post-hoc of Least-Significant Difference Test (LSD). 
$\pm 3.36 \%)$ than LB $40 \mu \mathrm{M}$ alone $(\mathrm{t}[14]=2.358, \mathrm{p}=0.025$; two independent sample $t$-test) (Figure 3C). Exposure to LB 40 $\mu \mathrm{M}+\mathrm{QX}-\mathrm{OH} 5 \mathrm{mM}$ produced a larger inhibition of the $I_{\mathrm{Na}}(83.88 \% \pm 1.57 \%)$ than exposure to LB $40 \mu \mathrm{M}$ alone $(\mathrm{t}[13]$ $=4.191, \mathrm{p}=0.0003$; two independent sample $t$-test) (Figure 3C). The inhibition of the $I_{\mathrm{Na}}$ was similar between the LB 40 $\mu \mathrm{M}+\mathrm{QX}-\mathrm{OH} 5 \mathrm{mM}$ and LB $40 \mu \mathrm{M}+\mathrm{QX}-\mathrm{OH} 2 \mathrm{mM}$ treatment groups $(\mathrm{t}[13]=1.703, \mathrm{p}=0.100$; two independent sample $t$-test) (Figure 3C). Because QX-OH exposure at $5 \mathrm{mM}$ inhibited the $I_{\mathrm{Na}}$ by $\sim 20 \%$, QX-OH and LB might produce an additive inhibition on the $I_{\mathrm{Na}}$.

After washout, the $I_{\mathrm{Na}}$ in the $40 \mu \mathrm{M}$ LB group was significantly higher than that of $40 \mu \mathrm{M} \mathrm{LB}+2 \mathrm{mM}$ QX-OH (t[13] $=3.017, \mathrm{p}=0.006$; two independent sample $t$-test) (Figure 3E), while the $I_{\mathrm{Na}}$ was markedly inhibited in LB $40 \mu \mathrm{M}+\mathrm{QX}-$ OH $5 \mathrm{mM}$ treatment group compared with exposure to LB $40 \mu \mathrm{M}$ alone $(\mathrm{t}[15]=-7.174, \mathrm{p}<0.0001$; two independent sample $t$-test) (Figure 3E). All the cells were alive without rundown during washout throughout and the recording could continue for a long time during the washout. Therefore, the co-application of QX-OH and LB produced a steady block of the $I_{\mathrm{Na}}$.

\section{LL-I Produced a Fast-Onset and Long-Lasting Sciatic Nerve Block in vivo}

The onset time of sensory and motor block by LL-1 and $10 \mathrm{mM} \mathrm{LB}$ were immediate after recovery from general anesthesia by isoflurane, which was recorded as $10 \mathrm{~min}$ for all the rats (Figure $4 \mathrm{~A}$ ). While the onset time of nerve block induced by exposure to $35 \mathrm{mM}$ QX-OH $(27[18,60] \mathrm{min}, \mathrm{t}[12]=-4.535, \mathrm{p}=0.001$; two independent sample $t$-test $)$, Figure 4D] was significantly delayed compared with exposure to LL-1.

The offset of sensory and motor block showed no significant difference among four groups (Figure 4B-E). There was a significant difference among the four groups in the duration of the sensory block $(F(3,35)=191.336, p<0.0001$, oneway ANOVA with Bonferroni post hoc test, Figure 4C). Exposure to LL-1 produced a sensory block with a total duration of $11(11.8,12.8) \mathrm{h}$, which was longer than that following exposure to QX-OH $[7.7(6.5,9) \mathrm{h}, \mathrm{t}(12)=11.419, \mathrm{p}<0.0001$; two independent sample $t$-test $]$, QX-314 $[11.6(9.7,11.6) \mathrm{h}, \mathrm{t}(7)=3.453, \mathrm{p}=0.009$; two independent sample $t$-test $]$ or LB
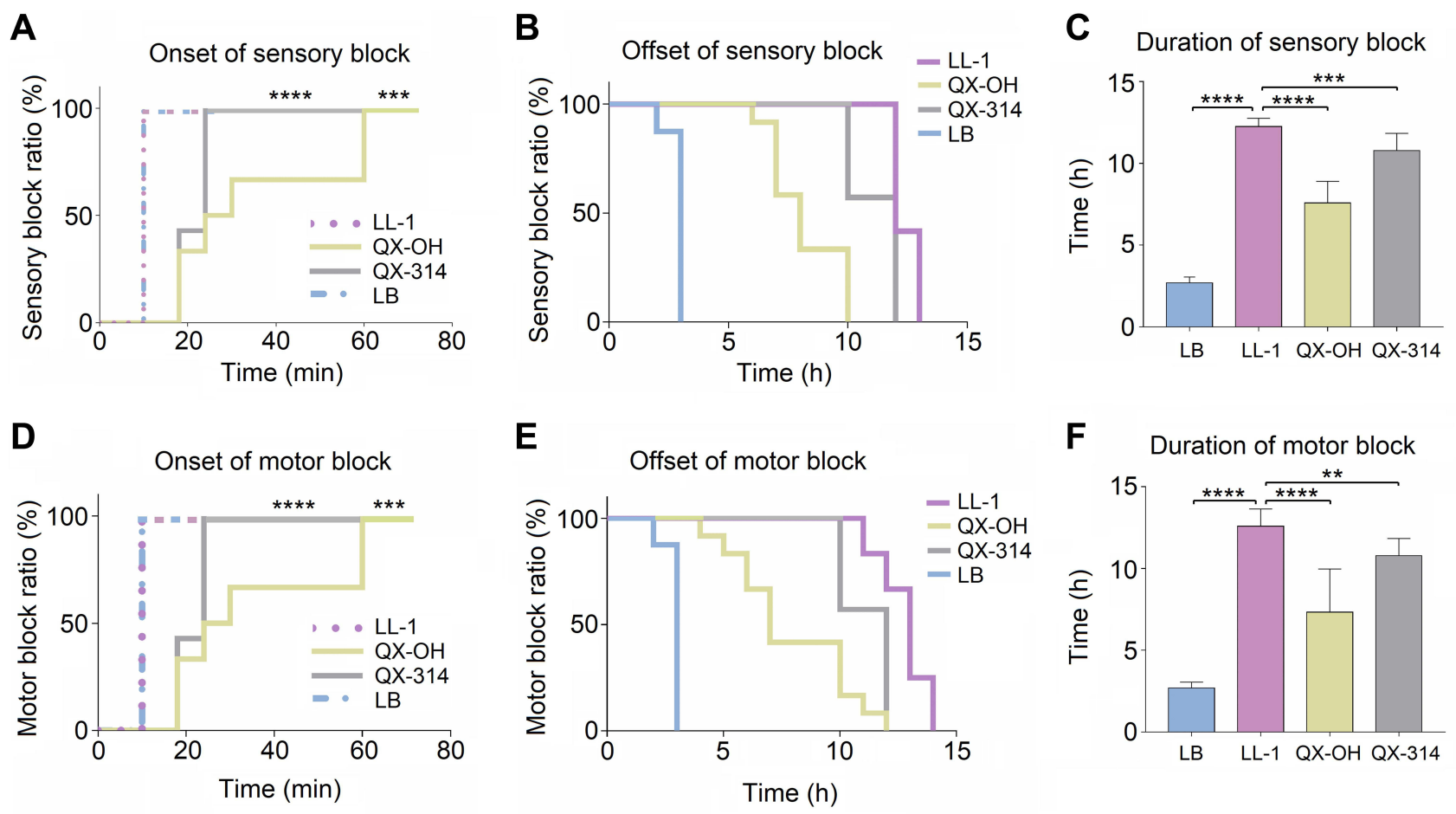

Figure 4 The onset, offset, and duration of sciatic nerve block after administration of LL-I (combination of $35 \mathrm{mM}$ QX-OH and $10 \mathrm{mM}$ LB), $35 \mathrm{mM}$ QX-OH, or $10 \mathrm{mM}$ LB. The onset of the sensory block $(\mathbf{A})$ and motor block $(\mathbf{B})$ in the sciatic nerve block; The time to recovery from nerve blockade: offset of sensory block (C) and motor block (D); The duration of sensory block (E) and motor block (F). Error bars represent the median (Interquartile range). $* * \mathrm{P}<0.0 \mathrm{I}$, $* * * \mathrm{p}<0.00 \mathrm{I}$, $* * * * \mathrm{P}<0.000 \mathrm{I}$ by MannWhitney U-test with post hoc Bonferroni analysis. 
[2.8 (2.8, 2.8), $\mathrm{t}(12)=11.419, \mathrm{p}<0.0001$; two independent sample $t$-test] (Figure 3C). For the motor block, the total duration of the four groups was significantly different $(\mathrm{F}[3,35]=63.052, \mathrm{p}<0.0001$, one-way ANOVA with Bonferroni post hoc test, Figure 4F). LL-1 produced a motor block with a total duration of $11(11.8,12.8) \mathrm{h}$, which was longer than that observed following exposure to QX-OH $[6.7(5.5,9.7) \mathrm{h}, \mathrm{t}(12)=6.393, \mathrm{p}=0.00015$; two independent sample $t$-test], QX-314 [11.6 $(9.7,11.6) \mathrm{h}, \mathrm{t}(7)=3.584, \mathrm{p}=0.002$; two independent sample $t$-test $]$ or to LB $[2.8(2.8,2.8)$ hour, $\mathrm{t}(12)$ $=29.989, \mathrm{p}<0.0001$; two independent sample $t$-test] (Figure 4F).

\section{Local Tissue Toxicity of LL-I Was Similar to LB Alone}

The tissue morphology indicated indistinguishable inflammation among rats who received LL-1 (Figure 5A, E, I and M), QX-OH (Figure 5B, F, J and N), LB (Figure 5C, G, K and O), and saline (Figure 5D, H, L and P). The inflammation scores of the sciatic nerve and skeletal muscle were $1(0,1)$ in the LL-1 group, which were not significantly different compared to the LB group $(0[0,1], \mathrm{t}[8]=-0.966, \mathrm{p}=0.35$; two independent sample $t$-test $)$, but was slightly higher than that observed in the saline group $(0[0,0], \mathrm{t}[8]=-3.416, \mathrm{p}=0.011$; two independent sample $t$-test $)$ on the 7 th day; and in the LL-1 group $0.5(0,1)$, compared within the LB group $(0[0,0.75], t[8]=-1, p=0.334$; two independent sample $t$-test) on the 14th day after recovery of nerve block. The inflammation scores of the sciatic nerve and skeletal muscle were higher than that in the saline group on 14 th day $(0[0,0], \mathrm{t}[8]=-2.646, \mathrm{p}=0.033$; two independent sample $t$-test) (Figure 5R and T). The pathological scores of nerve fiber degeneration were higher in the LL-1 group than that in the LB group on the 7 th day after nerve block ( $\mathrm{t}[8[=-4.583, \mathrm{p}=0.003$; two independent sample $t$-test, Figure $5 \mathrm{Q})$, which is higher than that in the saline group $(0[0,0], \mathrm{t}[8]=-4.583, \mathrm{p}=0.003$; two independent sample $t$-test $)$ while no differences were found on the 14th day between the two groups $(\mathrm{t}[8]=-0.607, \mathrm{p}=0.554$; two independent sample $t$-test), and there was no significant difference compared with the saline group on the 14 th day $(0[0,0], t[8]=-1.528, p=0.170$; two independent sample $t$-test). For other pathological scores including fibrosis and hemorrhage, no difference was found ( $\mathrm{p}>$ 0.05 by Kruskal-Wallis test) (Figure 5Q-T).

\section{Discussion}

Our present study indicates that LL-1 can produce a long-acting and fast-onset regional anesthetic effects with tissue toxicity similar to that of LB alone. The combination of QX-OH and LB induces a steady and additive inhibition of sodium currents, which may contribute to the fast-onset and long-acting nerve block of LL-1.

In our previous studies, we investigated the toxicity, pharmacokinetics, and pharmacodynamics of LL-1 in knee surgery and the sciatic nerve block rat model. ${ }^{7,8,10}$ LL-1 can provide sensory block with duration $\sim 9$ hour after knee surgery ${ }^{8}$ and regional anesthesia with duration $\sim 17$ hour in the sciatic nerve block rat models, ${ }^{6}$ while the toxicity of QX$\mathrm{OH}$ in local tissue was similar with a relevant concentration of LB. ${ }^{7,24}$ However, it is still unknown why a combination of QX-OH and LB can provide longer analgesia than either QX-OH or LB alone. To explore the possible mechanisms for the long-lasting nerve block of LL-1, we investigated the effects of LL-1 on voltage-gated sodium channels, which are the principal molecular target of local anesthetics.

The maximum reduction in $I_{\mathrm{Na}}$ showed an additive interaction for QX-OH and LB. The application of LB at a concentration of $\sim \mathrm{IC}_{50}$ induced a concentration-dependent inhibition of sodium currents by $65.51 \% \pm 3.63 \%$. The application of QX-OH alone at a concentration of $5 \mathrm{mM}$ reduced the $I_{\mathrm{Na}}$ by $19.28 \% \pm 11.47 \%$. When QX-OH was added to LB at the above-mentioned concentrations, the $I_{\mathrm{Na}}$ was reduced by $83.88 \% \pm 1.57 \%$. This result is below that reported in our previous study, we found that the neuron uptake of QX-OH was greater in LL-1 than QX-OH alone and the uptake of bupivacaine was similar the treatment group exposed to LL-1 with bupivacaine, which indicated an additive effect between QX-OH and LB. ${ }^{25}$ Thus, QX-OH and LB may produce an additive interaction on the inhibition of sodium currents.

In addition, the residual sodium currents quickly recovered after washout of $40 \mu \mathrm{M} \mathrm{LB}$, while these currents remained unchanged after washout of $40 \mu \mathrm{M} \mathrm{LB}+5 \mathrm{mM}$ QX-OH. These results indicated that the inhibition of the $\mathrm{I}_{\mathrm{Na}}$ induced by the combination of QX-OH and LB was more sustained than that observed by LB alone, which could at least partly account for the long-lasting regional anesthetic effects observed following exposure to LL-1. 
LL-1
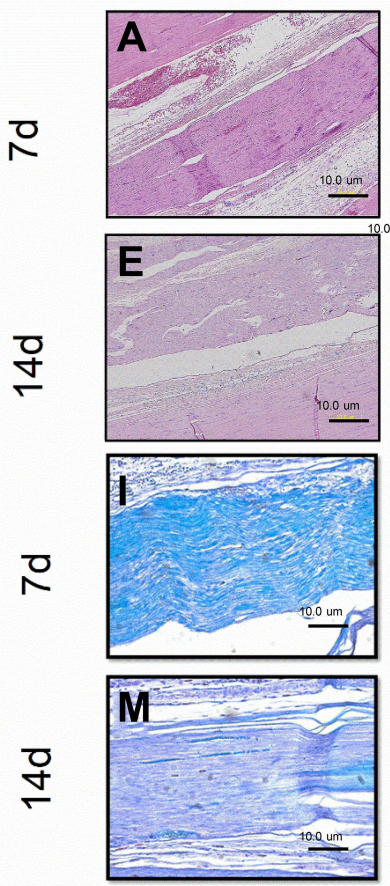

QX-OH
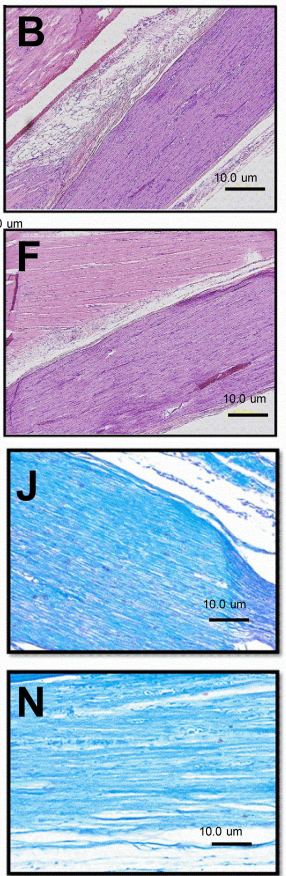

LB
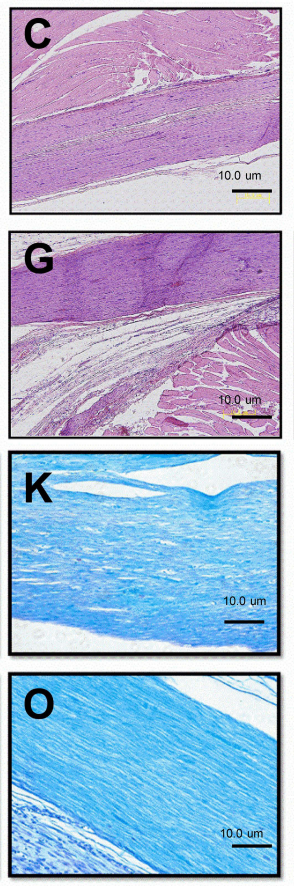

Saline
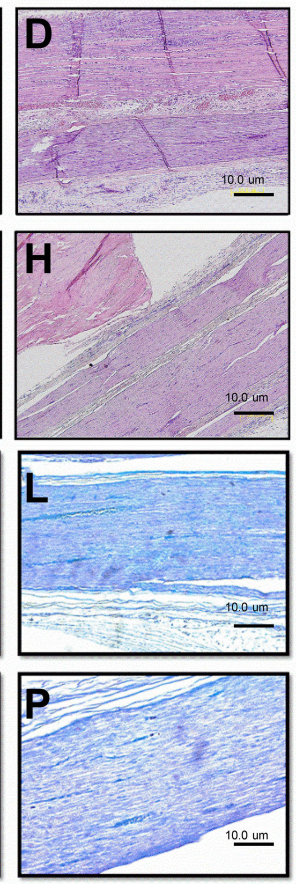
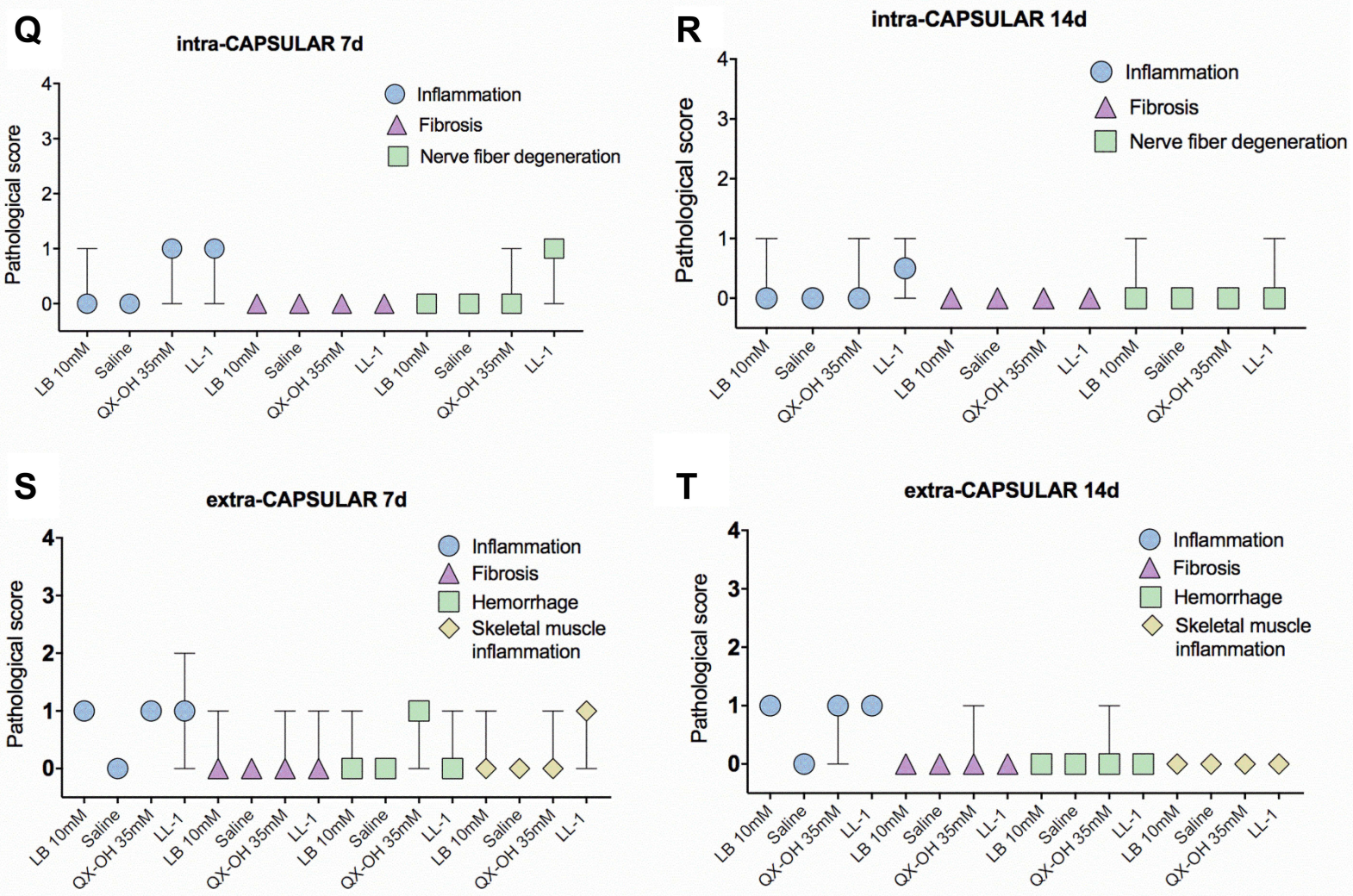

T

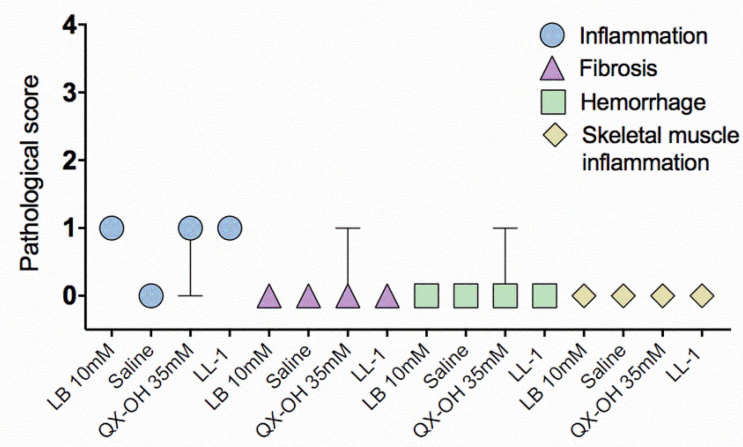

Figure 5 Representative images and pathological scores of histological sections at 7 and 14 days after sciatic nerve block. The pathological sections of four groups with $\mathrm{HE}$ and fast blue staining: HE: LL-I at 7 days (A) and I4 days (E); $35 \mathrm{mM}$ QX-OH at 7 days (B) and I4 days (F); 10 mM levobupivacaine at 7 days (C) and I4 days (G); Saline at 7 days (D) and I4 days (H). Fast blue staining: LL-I at 7 days (I) and I4 days (M); 35 mM QX-OH at 7 days (J) and I4 days (N); 10 mM levobupivacaine at 7 days (K) and I4 days (O); Saline at 7 days (L) and I 4 days (P). Intra-capsular pathological scores: 7 days (Q) and I4 days (R) after injection; Extra-capsular pathological scores: 7 days (S) and 14 days $(\mathbf{T})$ after injection. Data are presented as median and the range in each group. 
LL-1 shows a similar low degree of nerve inflammation compared to LB exposure at the corresponding concentration. The maximum of the inflammation scores following LL-1 exposure was one point, which revealed that QX-OH did not enhance the local tissue toxicity of LB, while LL-1 presented low local toxicity and a good safety profile. Co-injection of LAs with additives is a relatively better method when compared with continuous infusion of LAs or a controlled-release local anesthetic formulation, which both present a high risk of local tissue incompatibility, mechanical injury, and infections. ${ }^{23}$ The combination of QX-314 and bupivacaine has an acceptable safety profile. ${ }^{7}$ Moreover, QX-OH presents considerably lower local toxicity than QX-314 at the same concentration. ${ }^{7}$ Therefore, the combination of QX-OH and LB shows a higher possibility and value in clinical translation. In addition, in our experiment, we did not observe any behavioral manifestations of central nervous system or cardiac toxicities for LL-1.

Some new sodium channel blockers have been recently described. Selective $\mathrm{Na}_{\mathrm{v}} 1.7$ inhibitors are a research direction in the field of analgesia, Ahuja et al first described GX-936, a arylsulfonamide antagonists, and its related inhibitors could bind to the activated state of voltage-sensor domain IV and opposed VSD4 deactivation. ${ }^{26}$ Bankar et al made an additional improvement on the arylsulfonamides, and developed a $\mathrm{Na}_{\mathrm{v}} 1.7$ blocker with analgesic activity in inflammatory and neuropathic pain models having a 10-fold decrease in $\mathrm{EC}_{50}{ }^{27}$ Cannabidiol $^{26-28}$ is another type of analgesia; it non-selectively inhibits $\mathrm{Na}_{\mathrm{v}}$ channels from the inactivated state by preventing channel opening. Compared to these $\mathrm{Na}_{\mathrm{v}}$ channel blockers, LL-1 did not exert a direct effect on the $\mathrm{IC}_{50}$ and showed extremely prolonged block time. The different effects of LL-1 were mainly attributed to the special properties of its component QX-OH. QX-OH can only inhibit the $\mathrm{Na}_{\mathrm{v}}$ at concentrations over $5 \mathrm{mM}$, and the inhibition rate is only about $20 \%$. If the concentration is reduced, the inhibition rate of QX-OH is similar to that of the control group alone. Only when QX-OH was combined with LB at a certain ratio, can LL-1 increase its potency and persistently inhibit $\mathrm{Na}_{\mathrm{v}}$.

There are still limitations to our study. First, we speculated that there may be a synergetic or additive effect between QX-OH and LB both in nerve block and inhibition of $\mathrm{Na}_{\mathrm{v}}$. However, analysis of synergetic effects using isobologram analysis could not be performed because QX-OH only minimally inhibits $\mathrm{Na}_{\mathrm{v}}$ even at the $5 \mathrm{mM}$ concentration, thus we could not calculate the $\mathrm{IC}_{50}$ of QX-OH. Second, in the histological analysis, we use semi-quantitative assessment to evaluate the neuronal-specific damage, as $\mathrm{HE}$ and Fast blue staining are inadequate to precisely assess all the pathological features; histological analysis such as Masson's Trichrome stain and immunohistochemical staining may be needed in the subsequent studies.

\section{Conclusions}

LL-1 (QX-OH+LB) can produce a fast-onset and long-lasting regional anesthetic effects with low local tissue toxicity in rat sciatic nerve block models. QX-OH and LB induce additive and constant inhibition of sodium currents. The fastonset, remarkably long-lasting anesthetic effects, and low local tissue toxicity indicate the great potential for the clinical application of the QX-OH and LB combination.

\section{Acknowledgments}

The authors thank Li Li, Fei Chen, and Chunjuan Bao from the Institute of Clinical Pathology, West China Hospital of Sichuan University, for processing histological staining.

\section{Funding}

This work was supported by the National Natural Science Foundation of China (grants No. 81571353, J.L. and No. 81771486, C.Z.); and the Science \& Technology Department of Sichuan Province (2019YJ0029, C.Z.).

\section{Disclosure}

The authors report no conflicts of interest in this work.

\section{References}

1. de Boer HD, Detriche O, Forget P. Opioid-related side effects: postoperative ileus, urinary retention, nausea and vomiting, and shivering. A review of the literature. Best Pract Res Clin Anaesthesiol. 2017;31(4):499-504. doi:10.1016/j.bpa.2017.07.002 
2. Leone S, Di Cianni S, Casati A, Fanelli G. Pharmacology, toxicology, and clinical use of new long acting local anesthetics, ropivacaine and levobupivacaine. Acta Biomed. 2008;79(2):92-105.

3. Kuusniemi K, Poyhia R. Present-day challenges and future solutions in postoperative pain management: results from PainForum 2014. J Pain Res. 2016;9:25-36. doi:10.2147/JPR.S92502

4. Roberson DP, Binshtok AM, Blasl F, Bean BP, Woolf CJ. Targeting of sodium channel blockers into nociceptors to produce long-duration analgesia: a systematic study and review. Br J Pharmacol. 2011;164(1):48-58. doi:10.1111/j.1476-5381.2011.01391.x

5. Blumberg PM. Lighting a backfire to quench the blaze: a combined drug approach targeting the vanilloid receptor TRPV1. Mol Interv. 2007;7 (6):310-312. doi:10.1124/mi.7.6.5

6. Zhao W, Yin Q, Liu J, Zhang W, Yang L. Addition of dexmedetomidine to QX-314 enhances the onset and duration of sciatic nerve block in rats. Can J Physiol Pharmacol. 2018;96(4):388-394. doi:10.1139/cjpp-2017-0331

7. Zhang Y, Yang J, Yin Q, Yang L, Liu J, Zhang W. QX-OH, a QX-314 derivative agent, produces long-acting local anesthesia in rats. Eur J Pharm Sci. 2017;105:212-218. doi:10.1016/j.ejps.2017.05.039

8. Zhao W, Yang J, Zhang Y, Liu J, Zhang W. QX-OH/Levobupivacaine: fixed-dose combination to provide a long-acting postoperative pain of knee surgery in rodents. Eur J Pharm Sci. 2018;111:418-424. doi:10.1016/j.ejps.2017.10.025

9. Wang Q, Yin Q, Yang J, et al. Evaluation of the cardiotoxicity and resuscitation of rats of a newly developed mixture of a QX-314 analog and levobupivacaine. J Pain Res. 2017;10:737-746. doi:10.2147/JPR.S126396

10. Yin Q, Zhang Y, Lv R, et al. A fixed-dose combination, QXOH/ levobupivacaine, produces long-acting local anesthesia in rats without additional toxicity. Front Pharmacol. 2019;10:243. doi:10.3389/fphar.2019.00243

11. Kole MH, Ilschner SU, Kampa BM, Williams SR, Ruben PC, Stuart GJ. Action potential generation requires a high sodium channel density in the axon initial segment. Nat Neurosci. 2008;11(2):178-186. doi:10.1038/nn2040

12. Ruetsch YA, Boni T, Borgeat A. From cocaine to ropivacaine: the history of local anesthetic drugs. Curr Top Med Chem. 2001;1(3):175-182. doi:10.2174/1568026013395335

13. Catterall WA, Swanson TM. Structural basis for pharmacology of voltage-gated sodium and calcium channels. Mol Pharmacol. 2015;88(1):141150. doi:10.1124/mol.114.097659

14. Gawali VS, Lukacs P, Cervenka R, et al. Mechanism of modification, by lidocaine, of fast and slow recovery from inactivation of voltage-gated Na (+) channels. Mol Pharmacol. 2015;88(5):866-879. doi:10.1124/mol.115.099580

15. Jo S, Bean BP. Sidedness of carbamazepine accessibility to voltage-gated sodium channels. Mol Pharmacol. 2014;85(2):381-387. doi:10.1124/ mol.113.090472

16. Leffler A, Fischer MJ, Rehner D, et al. The vanilloid receptor TRPV1 is activated and sensitized by local anesthetics in rodent sensory neurons. $J$ Clin Invest. 2008;118(2):763-776. doi:10.1172/JCI32751

17. Wood JN, Bevan SJ, Coote PR, et al. Novel cell lines display properties of nociceptive sensory neurons. Proc Biol Sci. 1990;241(1302):187-194.

18. Stoetzer C, Martell C, de la Roche J, Leffler A. Inhibition of voltage-gated Na+ channels by bupivacaine is enhanced by the adjuvants buprenorphine, ketamine, and clonidine. Reg Anesth Pain Med. 2017;42(4):462-468. doi:10.1097/AAP.0000000000000596

19. Thalhammer JG, Vladimirova M, Bershadsky B, Strichartz GR. Neurologic evaluation of the rat during sciatic nerve block with lidocaine. Anesthesiology. 1995;82(4):1013-1025. doi:10.1097/00000542-199504000-00026

20. Shankarappa SA, Sagie I, Tsui JH, et al. Duration and local toxicity of sciatic nerve blockade with coinjected site 1 sodium-channel blockers and quaternary lidocaine derivatives. Reg Anesth Pain Med. 2012;37(5):483-489. doi:10.1097/AAP.0b013e31826125b3

21. Ossipov MH, Lopez Y, Nichols ML, Bian D, Porreca F. The loss of antinociceptive efficacy of spinal morphine in rats with nerve ligation injury is prevented by reducing spinal afferent drive. Neurosci Lett. 1995;199(2):87-90. doi:10.1016/0304-3940(95)12022-V

22. Feldman AT, Wolfe D. Tissue processing and hematoxylin and Eosin staining. Methods Mol Biol. 2014;1180:31-43.

23. Yin Q, Li J, Zheng Q, et al. The quaternary lidocaine derivative QX-314 in combination with bupivacaine for long-lasting nerve block: efficacy, toxicity, and the optimal formulation in rats. PLoS One. 2017;12(3):e0174421. doi:10.1371/journal.pone.0174421

24. Zhang Y, Yin Q, Gong D, et al. The preclinical pharmacological study of a novel long-acting local anesthetic, a fixed-dose combination of QX-OH/ levobupivacaine, in rats. Front Pharmacol. 2019;10:895. doi:10.3389/fphar.2019.00895

25. Zhang Y, Gong D, Zheng Q, Liu J, Zhang W. LC-MS/MS method for preclinical pharmacokinetic study of QX-OH, a novel long-acting local anesthetic, in sciatic nerve blockade in rats. J Pharm Biomed Anal. 2017;146:161-167. doi:10.1016/j.jpba.2017.07.028

26. Ahuja S, Mukund S, Deng L, et al. Structural basis of Nav1.7 inhibition by an isoform-selective small-molecule antagonist. Science (New York, NY). 2015;350(6267):aac5464

27. Bankar G, Goodchild SJ, Howard S, et al. Selective Na(V)1.7 Antagonists with Long Residence Time Show Improved Efficacy against Inflammatory and Neuropathic Pain. Cell reports. 2018;24(12):3133-3145.

28. Ghovanloo MR, Shuart NG, Mezeyova J, Dean RA, Ruben PC, Goodchild SJ. Inhibitory effects of cannabidiol on voltage-dependent sodium currents. J Biol Chem. 2018;293(43):16546-16558. doi:10.1074/jbc.RA118.004929

Journal of Pain Research

Dovepress

\section{Publish your work in this journal}

The Journal of Pain Research is an international, peer reviewed, open access, online journal that welcomes laboratory and clinical findings in the fields of pain research and the prevention and management of pain. Original research, reviews, symposium reports, hypothesis formation and commentaries are all considered for publication. The manuscript management system is completely online and includes a very quick and fair peer-review system, which is all easy to use. Visit http://www.dovepress.com/testimonials.php to read real quotes from published authors.

Submit your manuscript here: https://www.dovepress.com/journal-of-pain-research-journal 